\title{
VIOLENCIA,DIREITOS CIVISE DEMOGRAFIA NO BRASIL NA DÉCADA DE 80: o caso da Área Metropolitana do Rio de Janeiro
}

\section{Emilio Dellasoppa Alicia M. Bercovich Eduardo Arriaga}

\section{Introdução}

A década de 80 no Brasil foi um período de estagnação econômica e social, muitas vezes referido como a "década perdida". Aumentaram os indicadores associados à violência na sociedade, como a mortalidade por causas externas, crimes violentos e homicídios, e aumentou a desigualdade social, uma caraterística da estrutura social brasileira.

A incapacidade do Estado de controlar a violência e suas causas foi percebida e condenada por todos os setores sociais. A ausência de um planejamento estratégico consistente se fez evidente ao longo da década, assim como se faz no presente. Mas, ao mesmo tempo, o Brasil também experimentou melhoras nos seus processos e instituições políticas, sendo a democracia e os direitos civis plenamente restabelecidos depois de duas décadas de regime autoritário. Desafortunadamente, na década de 80 verifica-se também um aumento sistemático em indicadores de violência tais como índices de mortalidade e número de anos perdidos por causas violentas, aumento que continua no presente, porém em porcentagens menores, sugerindo uma desaceleração no processo. Estes indicadores têm sido piores para os grupos etários mais jovens, um resultado consistente com as tendências internacionais.

Junto com os indicadores, o medo e a insegurança têm aumentado em todos os setores sociais, desde os muito pobres até os muito ricos. Porém, 0 tipo de incidentes violentos que os cidadãos brasileiros estão propensos a sofrer varia amplamente quanto a suas causas, natureza e probabilidade, dependendo fortemente da faixa etária, da renda, e da região onde se mora e trabalha. A extrema desigualdade que notávamos antes nos indicadores sociais manifesta-se também nessa grande variabilidade dos riscos (Cedec, 1996 e 1997).

Neste artigo observamos uma relação inversa entre 0 processo de democratização experimentado pelo Brasil e o aumento dos níveis de violência na sociedade brasileira, medidos pelas estatísticas de mortalidade. Analisamos as taxas de mortalidade por causas externas e estendemos a pesquisa ao número de anos de vida perdidos por causas violentas nos municípios da Região Metropolitana do Rio de Janeiro (RMRJ). Realizamos comparações com a Região Metropolitana de São Paulo (RMSP), outras regiões do Brasil e Buenos Aires. A relação entre a violência e a estrutura das relações sociais foi mapeada com base em um número de caraterís- 
ticas específicas observadas no Brasil e na RMRJ. Este mapeamento baseia-se numa concepção da presente estrutura de relações sociais que, como produto humano, inclui entre seus componentes as diferentes manifestações da violência, entendida como um dos produtos sociais da externalização humana na produção dessa estrutura de relações sociais. $^{1}$ Finalmente, sugere-se que a pesquisa interdisciplinar é o melhor caminho para desvendar os determinantes socioeconômicos dessa situação e uma contribuição importante ao debate sobre direitos civis e ação afirmativa em relação ao problema da violência urbana, que consideramos ser um problema de saúde pública.

\section{Dados e métodos}

Os dados de mortes por causas externas e homicídios utilizados nesta análise provêm do SIM - Sistema de Informação sobre Mortalidade (Ministério da Saúde, 1996), das estatísticas vitais (FIBGE, 1979, 1980, 1981, 1990, 1991 e 1992) e dos censos brasileiros (FIBGE, 1980 e 1991). Os códigos das causas de morte utilizados pelo SIM são os Códigos E da Nona Revisão da Classificação Internacional de Doenças (CID - BR). ${ }^{2}$ Foram utilizadas médias de três anos para minimizar a variação estatística nos dados. ${ }^{3}$

Para avaliar as mudanças nas mortes por causas naturais e violentas, analisamos as mudanças verificadas nas taxas de mortalidade por causas e grupos de idade entre 1980 e 1991. Para uma avaliação quantitativa das mortes violentas e não violentas, foi usado o método de anos de vida perdidos (Arriaga, 1984). Este método permite a análise das mudanças na mortalidade por causa individual e grupos de idade, bem como para 0 conjunto de grupos de idades combinados. 0 número de anos de vida perdidos não mede diretamente a mudança da mortalidade, senão o impacto da mudança da mortalidade na vida da população, do mesmo modo que na esperança de vida ao nascer.

0 método dos anos de vida perdidos leva em conta a idade da pessoa que morre e refere-se diretamente à mudança das esperanças de vida. 0 número de anos de vida perdidos calculado neste artigo é a medida do número de anos de vida ou da esperança temporária de vida entre as idades analisadas que são perdidos devido à mortalidade por causas violentas ou não violentas. A diferença entre os anos de vida perdidos na mesma área (por exemplo, no mesmo município) entre um ano e outro indica a variação na esperança temporária de vida devida à mudança da mortalidade por diferentes causas de morte. Se considerarmos áreas diferentes (e portanto populações diferentes), a diferença entre 0 número de anos de vida perdidos entre as duas populações evidencia a mudança na esperança temporária de vida que teria acontecido em uma população se 0 nível de mortalidade por uma causa específica de morte para essa população fosse igual ao nível da outra população.

Por exemplo, se compararmos as regiões metropolitanas do Rio de Janeiro e de São Paulo, a diferença em anos de vida perdidos mostra 0 incremento na esperança temporária de vida entre 15 e 64 anos que teria ocorrido se a mortalidade da população da RMRJ igualasse a mortalidade observada na RMSP para cada causa de morte. Foi realizada a análise para as idades entre 15 e 64 anos, e comparada a mortalidade atual com o suposto de mortalidade nula entre essas idades. 0 estudo foi focalizado nessas idades porque as mortes violentas afetam fundamentalmente os homens jovens, e para excluir grupos etários com mortalidade alta originada em outras causas, como as crianças e os idosos. ${ }^{4}$

\section{Resultados}

A Figura 1 mostra, para os homens, os anos perdidos por causas violentas e grupos etários na RMRJ. Todos os grupos etários, com exceção do grupo de 55-64 anos, que permanece constante, mostram importantes aumentos no número de anos de vida perdidos. 0 resultado é ainda mais dramático para o grupo de 15-24 anos, com um aumento de $100 \%$ acima dos valores de 1980 , que já eram altos. 0 número total de anos perdidos por causas externas eleva-se de 2,05 para 3,26. Este é um aumento significativo, se compararmos aos valores equivalentes para a Região Sul em 1991, 1,48 anos, ou para a Argentina durante 0 mesmo período, 0,79 anos (Tabela 1). 0 impacto deste aumento da mortalidade nos homens do grupo etário 15-24 
Tabela 1

Número de anos pendidos por causas - Homens

\begin{tabular}{crrrrr} 
& \multicolumn{5}{c}{ Anos de vida perdidos entre 15 e 64 anos } \\
Anos & RMRJ & RMSP & SUL & SUDESTE & ARGENTINA \\
\hline 1980 & 6,85 & 5,77 & 5,16 & 5,92 & \\
1991 & 8,08 & 7,09 & 4,81 & 6,26 & 3,76 \\
Incremento do número de anos perdidos & 1,23 & 1,32 & $-0,34$ & 0,34 & \\
Incremento relativo (\%) & $17,93 \%$ & $22,81 \%$ & $-6,64 \%$ & $5,78 \%$
\end{tabular}

\begin{tabular}{rrrrrr} 
& \multicolumn{5}{c}{ Anos perdidos entre 15 e 64 anos por causas naturais } \\
& RMRJ & RMSP & SUL & SUDESTE & ARGENTINA \\
\hline 1980 & 4,80 & 4,17 & 3,84 & 4,45 & \\
1991 & 4,82 & 4,61 & 3,33 & 4,33 & 2,98
\end{tabular}

Incremento do número de anos perdidos por causas naturais Incremento relativo (\%) por causas naturais

$\begin{array}{rrrr}0,03 & 0,44 & -0,50 & -0,12 \\ 0,54 \% & 10,51 \% & -13,11 \% & -2,77 \%\end{array}$

Anos perdidos entre 15 e 64 anos por causas violentas

1980

1991

Incremento do número de anos perdidos por causas violentas Incremento relativo (\%) por causas violentas $5857 \%$

\begin{tabular}{rrrcc} 
RMRJ & RMSP & SUL & SUDESTE & ARGENTINA \\
\hline 2,05 & 1,60 & 1,32 & 1,47 & \\
3,26 & 2,48 & 1,48 & 1,94 & 0,79
\end{tabular}

$1,20 \quad 0,88 \quad 0,16 \quad 0,47$

Fonte: IBGE, Estatísticas do Registro Civil, 1979, 1980, 1981, 1990, 1991 e 1992.

Figura 1

Anos perdidos por causas violentas e grupos etánios Homens RMRJ 1980-1991

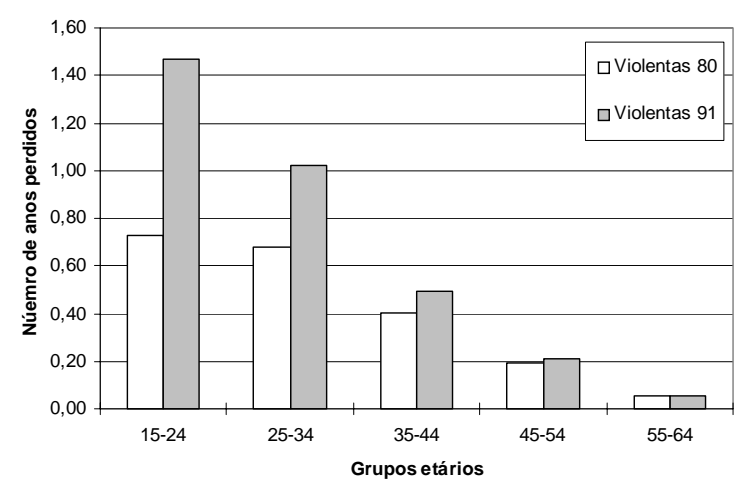

anos é tão importante que poderá influenciar negativamente ou ainda reduzir a esperança de vida do grupo masculino na sua totalidade. Se levarmos também em conta que a população brasileira encontra-se sob o impacto de uma nova "onda jovem" (Bercovich e Madeira, 1990), ${ }^{5}$ isto poderá implicar um número de mortes violentas excepcionalmente alto na década de 90 .
Existem notáveis diferenças entre as duas mais importantes áreas metropolitanas do Brasil, Rio de Janeiro e São Paulo. ${ }^{6} \mathrm{Na}$ RMSP, o número de anos perdidos por causas naturais entre os homens cresceu nos primeiros três grupos, com um máximo absoluto de 0,33 anos perdidos (aumento de 57,9\%) para os homens no grupo etário 25-34 anos, e um máximo relativo representando $60,6 \%$ de crescimento para homens entre 15 e 24 anos $(0,20$ anos perdidos). Em contraste com o Rio de Janeiro, na RMSP até os homens no grupo etário entre 35 e 44 anos experimentaram um crescimento no número de anos perdidos por causas naturais, em relação a 1980. Este aumento é atribuído à epidemia da AIDS, que mostra um rápido crescimento nas estatísticas desde 1988 (Waldvogel, 1992). Ainda, ao observarmos o número de anos perdidos pelos homens em 1991 na RMSP por causas violentas e por grupos etários, tendo como base de comparação 1980, notamos um padrão semelhante, em níveis mais baixos, àquele encontrado na RMRJ.

Quando consideramos a proporção de mortes violentas e a proporção do total do número de anos 
perdidos por causa da violência para homens e mulheres, nas diferentes regiões do Brasil, notamos, primeiro, que a proporção de anos perdidos por causa da violência é sempre mais alta do que a proporção de mortes violentas. Isso se dá como conseqüência da tendência de mortes violentas entre jovens, como verificado por Arriaga (1994). Como as mortes violentas acontecem fundamentalmente entre jovens, os anos que esses jovens ainda teriam para viver são muito importantes quantitativamente: $40 \%$ do total de anos perdidos pelos homens entre 15 e 64 anos na RMRJ é devido a causas violentas; na Região Sul do Brasil e na Argentina (Região Metropolitana de Buenos Aires) essa proporção cai para $31 \%$ e $20 \%$, respectivamente. Em segundo lugar, notamos que os números são mais elevados no sexo masculino do que no feminino, seguindo o padrão encontrado em outros países onde ocorre um número significativo de mortes por causas externas. Terceiro, importantes diferenças entre as regiões podem ser observadas em relação ao número de anos perdidos. Para efeito de comparação, incluímos os valores da Argentina em 1991, que são muito mais baixos para os homens, mas que mostram os mesmos padrões observados para as mulheres de diferentes regiões do Brasil.

A Figura 2 mostra os incrementos no número de anos perdidos por causas e grupos etários dos homens, de 1980 a 1991, na Região Metropolitana do Rio de Janeiro. Devemos notar que o número de anos perdidos por causas e grupos etários na RMSP é mais elevado do que na RMRJ para os primeiros dois grupos etários, quase equivalente no grupo entre 35 e 44 anos, e mais baixo para os últimos dois grupos. Além disso, na RMSP o incremento de anos perdidos por causas naturais é positivo até mesmo para o grupo entre 15 e 24 anos, contrastando, desta forma, com o pequeno decréscimo experimentado na RMRJ.

Outra diferença é o peso relativo das causas naturais e violentas. $\mathrm{Na}$ RMRJ, todo o incremento no número de anos perdidos no grupo de 15-24 anos provém de causas violentas, contra um pequeno decréscimo para causas naturais. Na RMSP, no entanto, para o mesmo grupo etário, 30\% do crescimento no número de anos perdidos deve-se a causas naturais. Para o grupo etário de 25-34 anos
Figura 2

Incremento no número de anos perdidos por causa e grupo etánio - Homens RMRJ 1980-1991

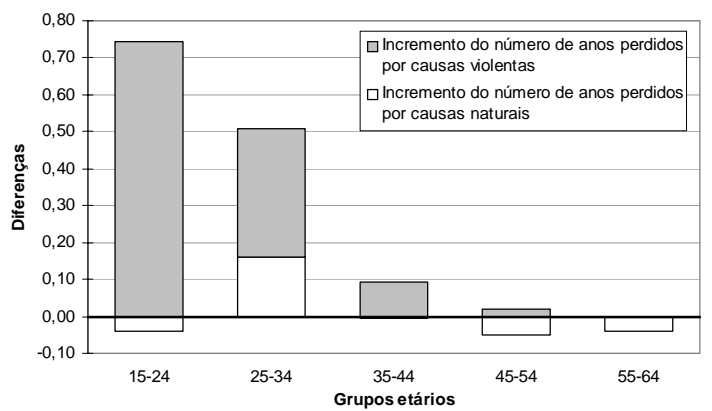

Figura 3

Incremento no número de anos perdidos por causa e grupo etánio - Mulheres RMRJ 1980-1991

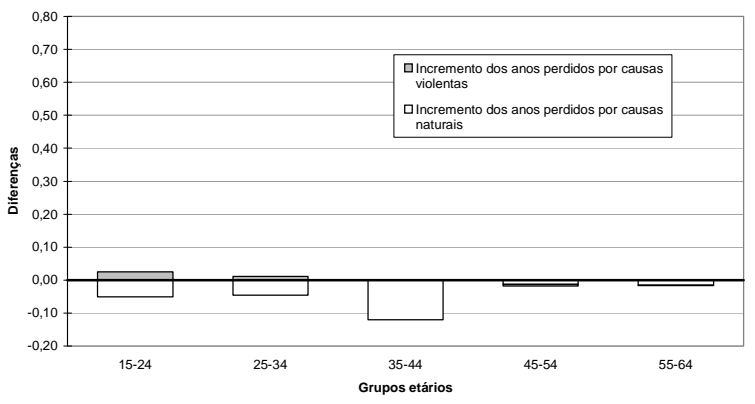

Figura 4

Incremento no número de anos perdidos entre 1980-1991. Homens e Mulheres de 15 a 64 anos

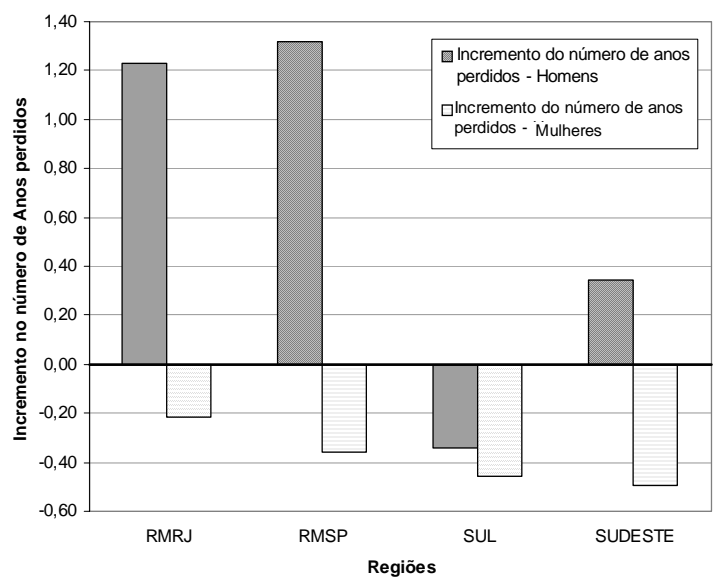

a diferença é notável: 0 incremento no número de anos perdidos por causas naturais responde por $31,4 \%$ do crescimento total na RMRJ, ao passo que na RMSP ele responde por 55\% do total (Tabela 2).

A Figura 3 mostra os incrementos no número de anos perdidos por causas e grupos etários para as mulheres na RMRJ entre 1980 e 1991. Observa- 
Tabela 2

Númeno de anos perdidos por causas e grupos de idade - Homens

RMRJ

\begin{tabular}{lrrrrrr}
\hline Causas & $15-24$ & $25-34$ & $35-44$ & $45-54$ & $55-64$ & TOTAL \\
\hline Naturais 80 & 0,54 & 0,73 & 1,18 & 1,48 & 0,86 & 4,80 \\
Violentas 80 & 0,73 & 0,68 & 0,40 & 0,19 & 0,05 & 2,05 \\
Naturais 91 & 0,50 & 0,90 & 1,18 & 1,43 & 0,83 & 4,82 \\
Violentas 91 & 1,47 & 1,03 & 0,50 & 0,21 & 0,05 & 3,26 \\
\hline Aumento em anos perdidos, causas naturais & $-0,04$ & 0,16 & $-0,01$ & $-0,05$ & $-0,04$ & 0,03 \\
Aumento em anos perdidos, causas violentas & 0,74 & 0,35 & 0,09 & 0,02 & 0,00 & 1,20
\end{tabular}

RMSP

\begin{tabular}{lccccccc}
\hline Causas & $15-24$ & $25-34$ & $35-44$ & $45-54$ & $55-64$ & TOTAL \\
\hline Naturais 80 & 0,34 & 0,57 & 1,06 & 1,37 & 0,83 & 4,17 \\
Violentas 80 & 0,63 & 0,45 & 0,30 & 0,17 & 0,05 & 1,60 \\
Naturais 91 & 0,58 & 0,90 & 1,09 & 1,29 & 0,75 & 4,61 \\
Violentas 91 & 1,19 & 0,71 & 0,36 & 0,17 & 0,04 & 2,48 \\
\hline Aumento em anos perdidos, causas naturais & 0,24 & 0,33 & 0,03 & $-0,08$ & $-0,08$ & 0,44 \\
Aumento em anos perdidos, causas violentas & 0,56 & 0,27 & 0,06 & 0,01 & $-0,01$ & 0,88
\end{tabular}

Região Sudeste

\begin{tabular}{lrrrrrr}
\hline Causas & $15-24$ & $25-34$ & $35-44$ & $45-54$ & $55-64$ & TOTAL \\
\hline Naturais 80 & 0,41 & 0,69 & 1,15 & 1,40 & 0,81 & 4,45 \\
Violentas 80 & 0,50 & 0,46 & 0,30 & 0,16 & 0,04 & 1,47 \\
Naturais 91 & 0,45 & 0,78 & 1,06 & 1,29 & 0,75 & 4,33 \\
Violentas 91 & 0,79 & 0,61 & 0,34 & 0,16 & 0,04 & 1,94 \\
\hline Aumento em anos perdidos, causas naturais & 0,04 & 0,09 & $-0,09$ & $-0,11$ & $-0,06$ & $-0,12$ \\
Aumento em anos perdidos, causas violentas & 0,29 & 0,14 & 0,03 & 0,00 & 0,00 & 0,47
\end{tabular}

Região Sul

\begin{tabular}{lrrrrrrc}
\hline Causas & $15-24$ & $25-34$ & $35-44$ & $45-54$ & $55-64$ & TOTAL \\
\hline Naturais 80 & 0,38 & 0,51 & 0,90 & 1,25 & 0,80 & 3,84 \\
Violentas 80 & 0,41 & 0,40 & 0,29 & 0,17 & 0,05 & 1,32 \\
Naturais 91 & 0,30 & 0,45 & 0,72 & 1,11 & 0,76 & 3,33 \\
Violentas 91 & 0,53 & 0,44 & 0,29 & 0,17 & 0,05 & 1,48 \\
\hline Aumento em anos perdidos, causas naturais & $-0,08$ & $-0,07$ & $-0,18$ & $-0,14$ & $-0,04$ & $-0,50$ \\
Aumento em anos perdidos, causas violentas & 0,12 & 0,05 & $-0,01$ & 0,00 & 0,00 & 0,16 \\
\hline
\end{tabular}

Fonte: IBGE, Estatísticas do Registro Civil, 1979, 1980, 1981, 1990, 1991 e 1992.

mos um pequeno crescimento no número de anos perdidos por causa da violência no grupo etário de 15-24 anos. Na RMSP, temos uma diminuição do número de anos perdidos em todas as faixas etárias. Este quadro obtido para as mulheres aponta marcantes diferenças ao ser comparado aos resultados apresentados para os homens. Na Figura 4 apresentam-se os incrementos no número de anos perdidos para homens e mulheres entre 15 e 64 anos nas regiões Sul e Sudeste e nas áreas metropolitanas do Rio de Janeiro e de São Paulo. Tanto na Região Sudeste como nessas áreas metropolitanas aparecem consideráveis incrementos no número de anos de vida perdidos pelos homens, e aumento 
da esperança de vida temporária das mulheres, por todas as causas. A influência da RMRJ e da RMSP leva a um resultado líquido positivo em número de anos perdidos para a Região Sudeste, onde essas áreas metropolitanas estão localizadas.

Resumindo os resultados anteriores, podemos verificar que quando consideramos o número de anos perdidos pelos homens, por regiões e causas, observamos diferenças no peso relativo das causas entre a RMRJ e a RMSP, assim como um contraste com a Região Sul, que apresenta um valor negativo. No caso das mulheres, o contraste com 0 resultado obtido para os homens é evidente em todas as regiões (Tabela 3). No caso dos homens, quando comparamos o número de anos perdidos por tipo de causa entre 1980 e 1991 nas duas áreas

Tabela 3

Número de anos perdidos por causas e grupos de idade - Mulheres

\section{RMRJ}

Causas

Naturais 80

Violentas 80

Naturais 91

Violentas 91

Aumento em anos perdidos, causas naturais

Aumento em anos perdidos, causas violentas

15-24

$0,30-25-34$

$0,11 \quad 0,10$

$0,25 \quad 0,42$

$0,13 \quad 0,11$

$\begin{array}{rr}-0,05 & -0,05 \\ 0,03 & 0,01\end{array}$

$0,03 \quad 0,01$

35-4

0,75

0,75

0,07

0,63

$0,07-0,04$

0,07

0,00

45-54

0,85

0,05

0,84

0,04

0,00

55-64 TOTAL

$0,02 \quad 0,34$

$0,51 \quad 2,64$

$\begin{array}{rr}0,02 & 0,37 \\ -0,02 & -0,25\end{array}$

$0,00 \quad 0,03$

\section{RMSP}

\begin{tabular}{llrrrrrr}
\hline Causas & $15-24$ & $25-34$ & $35-44$ & $45-54$ & $55-64$ & TOTAL \\
\hline Naturais 80 & 0,26 & 0,37 & 0,64 & 0,80 & 0,50 & 2,57 \\
Violentas 80 & 0,11 & 0,07 & 0,06 & 0,04 & 0,01 & 0,29 \\
Naturais 91 & & 0,23 & 0,34 & 0,50 & 0,71 & 0,45 & 2,22 \\
Violentas 91 & 0,11 & 0,08 & 0,05 & 0,03 & 0,01 & 0,28 \\
\hline Aumento em anos perdidos, causas naturais & $-0,03$ & $-0,04$ & $-0,14$ & $-0,09$ & $-0,05$ & $-0,35$ \\
Aumento em anos perdidos, causas violentas & 0,00 & 0,00 & $-0,01$ & 0,00 & 0,00 & $-0,01$
\end{tabular}

\section{Região Sudeste}

\begin{tabular}{lrrrrrr}
\hline Causas & $15-24$ & $25-34$ & $35-44$ & $45-54$ & $55-64$ & TOTAL \\
\hline Naturais 80 & 0,29 & 0,46 & 0,73 & 0,82 & 0,51 & 2,82 \\
Violentas 80 & 0,10 & 0,08 & 0,05 & 0,04 & 0,01 & 0,27 \\
Naturais 91 & 0,23 & 0,36 & 0,54 & 0,73 & 0,46 & 2,32 \\
Violentas 91 & 0,10 & 0,08 & 0,05 & 0,03 & 0,01 & 0,27 \\
\hline Aumento em anos perdidos, causas naturais & $-0,06$ & $-0,10$ & $-0,19$ & $-0,10$ & $-0,05$ & $-0,50$ \\
Aumento em anos perdidos, causas violentas & 0,00 & 0,00 & 0,00 & 0,00 & 0,00 & 0,00
\end{tabular}

\section{Região Sul}

\begin{tabular}{lrrrrrrc}
\hline Causas & $15-24$ & $25-34$ & $35-44$ & $45-54$ & $55-64$ & TOTAL \\
\hline Naturais 80 & 0,26 & 0,38 & 0,62 & 0,74 & 0,49 & 2,49 \\
Violentas 80 & 0,09 & 0,06 & 0,05 & 0,03 & 0,01 & 0,24 \\
Naturais 91 & 0,19 & 0,27 & 0,45 & 0,65 & 0,43 & 2,00 \\
Violentas 91 & 0,10 & 0,07 & 0,05 & 0,04 & 0,01 & 0,27 \\
\hline Aumento em anos perdidos, causas naturais & $-0,07$ & $-0,11$ & $-0,17$ & $-0,09$ & $-0,06$ & $-0,49$ \\
Aumento em anos perdidos, causas violentas & 0,02 & 0,01 & 0,00 & 0,00 & 0,00 & 0,03 \\
\hline
\end{tabular}

Fonte: IBGE, Estatísticas do Registro Civil, 1979, 1980, 1981, 1990, 1991 e 1992. 
metropolitanas e nas regiões Sul e Sudeste, chama a atenção o incremento de $10 \%$ no número de anos perdidos por causas naturais na RMSP.

Já nas regiões Sul e Sudeste observa-se um aumento da esperança de vida temporária devido à diminuição da mortalidade por causas não violentas e, ao mesmo tempo, um aumento no número de anos perdidos por causa da violência. Os maiores incrementos estão na RMRJ e na RMSP. D eve ser levado em conta que o incremento na Região Sul é calculado com base em valores absolutos muito menores. Esta observação é válida para as mulheres em todos os casos. Observa-se que a mortalidade das mulheres apresenta incrementos relativos positivos na RMRJ e na Região Sul, mas com valores absolutos muito baixos, resultados compatíveis com as tendências internacionais.

\section{Anos perdidos devido à violência nos municípios da área metropolitana do Rio de Janeiro}

Aproximadamente $80 \%$ da população do Estado do Rio de Janeiro está concentrada na sua área metropolitana. A Tabela 4 apresenta a listagem dos municípios pertencentes à área metropolitana, suas populações em 1980 e 1991 e as taxas de crescimento no período?

Os indicadores socioeconômicos são extremamente diferentes entre os municípios da RMRJ e até mesmo no interior de cada município, mas no presente estágio de desenvolvimento desta pesquisa esses indicadores não estão incluídos em uma relação de causa. Não existe consenso sobre este ponto, que permanece extremamente controverso. Vários autores sustentam que "fatores subjacentes aos precursores imediatos [da violência] podem incluir a pobreza, as oportunidades sociais e econômicas inadequadas, a instabilidade social e familiar e a freqüente exposição pessoal à violência como um meio aceitável ou preferível de resolver desavenças" (Reiss e Roth, 1993; NCIPC e CDC, 1989). No entanto, outros (Coelho, 1988) não encontram nenhuma relação entre os níveis de pobreza e os de violência. A próxima etapa deste trabalho deverá incluir considerações relacionando desigualdade e níveis de anos perdidos por causas violentas.

A Figura 5 mostra o número de anos perdidos devido à violência nos municípios da RMRJ, entre 1980 e 1991. Podemos observar dois grupos de municípios: o primeiro, composto de municípios (São Gonçalo, Paracambi, Nilópolis, São João de

\section{Tabela 4}

\section{Municípios da Região Metropolitana do Rio de Janeiro. População 1980-1991}

\begin{tabular}{lrrc} 
Municípios & $\mathbf{1 9 8 0}$ & $\mathbf{1 9 9 1}$ & Taxa de \\
\hline Estado do Rio de Janeimo. Total & 11.291 .520 & 12.807 .706 & $1,15 \%$ \\
\hline Região Metropolitana & 8.772 .265 & 9.814 .574 & $1,03 \%$ \\
\hline Rio de Janeiro & 5.090 .700 & 5.480 .768 & $0,67 \%$ \\
Duque de Caxias & 575.814 & 667.821 & $1,36 \%$ \\
Itaboraí & 114.540 & 162.742 & $3,24 \%$ \\
Itaguaí & 90.133 & 113.057 & $2,08 \%$ \\
Magé & 166.602 & 191.734 & $1,29 \%$ \\
Mangaratiba & 13.845 & 17.925 & $2,38 \%$ \\
Maricá & 32.618 & 46.545 & $3,29 \%$ \\
Nilópolis & 151.588 & 158.092 & $0,38 \%$ \\
Niterói & 397.123 & 436.155 & $0,86 \%$ \\
Nova Iguaçu & 1.094 .805 & 1.297 .704 & $1,56 \%$ \\
Paracambi & 30.319 & 36.427 & $1,68 \%$ \\
São Gonçalo & 615.352 & 779.832 & $2,18 \%$ \\
São João de Meriti & 398.826 & 425.772 & $0,60 \%$ \\
\hline
\end{tabular}

Fonte: Fundação Instituto Brasileiro de Geografia e Estatística - FIBGE, Censos Demográficos 1980 e 1991. 
Figura 5

Número de anos perdidos por causas violentas - Homens Municípios da Região Metropolitana do Rio de Janeiro, 1980-1991

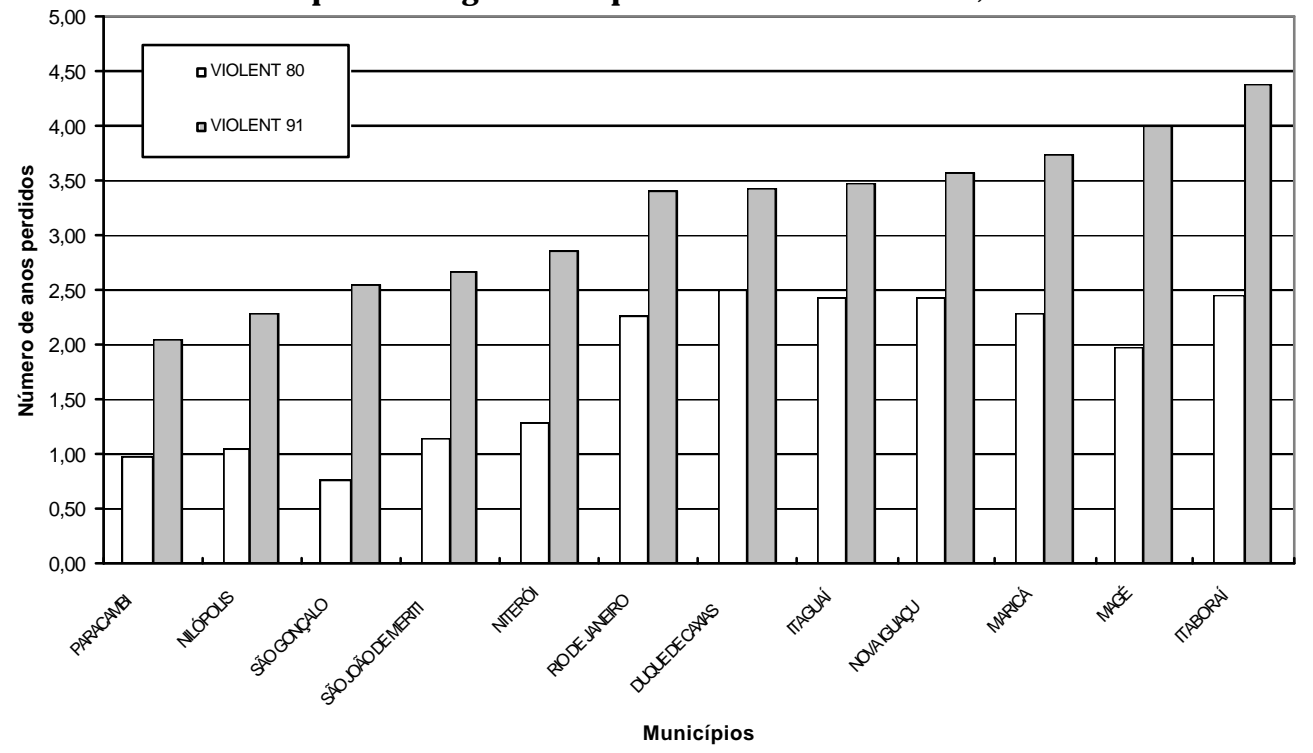

Meriti e Niterói) com um número de anos perdidos em 1980 entre 0,75 e 1,25; o segundo, composto por municípios (Rio de Janeiro, Maricá, Itaguaí, Nova Iguaçu, Itaboraí e Duque de Caxias) com um número de anos perdidos em 1980 que oscilava entre 2 e 2,5. Um grupo residual é composto por dois municípios que não apresentaram freqüências suficientes para serem incluídos na análise. Observamos também que em 1991 aparecem novamente os dois grupos de municípios, porém com número de anos perdidos em níveis mais altos em todos os casos, numa generalização do aumento dos anos perdidos em toda a área metropolitana do Rio de Janeiro. Os resultados mostram o crescimento da violência: no primeiro grupo houve um incremento para 2-3 anos perdidos, e no segundo para 3-4,5 anos perdidos. Para a RMRJ como um todo, houve um crescimento importante no número de anos perdidos por homens em 1980-91. A Figura 5 mostra como as condições pioraram no Município de São Gonçalo, onde houve um crescimento de quase $240 \%$ no número de anos perdidos devido à violência. São Gonçalo faz divisa com Niterói, outro município com um crescimento de quase $120 \%$ no número de anos perdidos, mas mesmo assim apresentando níveis mais baixos do que a maioria dos municípios da RMRJ.

\section{Homicídios, acidentes de trânsito e outras causas de morte na RMRJ}

Como foi mostrado antes (Tabelas 1, 2 e 3), em todas as regiões consideradas houve um crescimento tanto na proporção de mortes violentas quanto na proporção de anos perdidos devido à violência. Como conseqüência do impacto dessas mortes nas coortes jovens, observamos que o crescimento da proporção de anos perdidos devido à violência é sempre maior do que o crescimento da proporção de mortes violentas no total das mortes. Os padrões para homens e mulheres são semelhantes em todas as regiões, com uma razão homem/ mulher de aproximadamente 3 para 1. Vamos agora nos deter na RMRJ e no Município do Rio de Janeiro e analisar sumariamente os componentes principais do grupo de causas violentas: acidentes de trânsito de veículos a motor, homicídios e demais causas externas.

De acordo com a pesquisa de Lopes (1994), dados sobre homicídios são geralmente subestimados e mortes por outras causas não definidas devem ser incluídas nos homicídios, deixando de lado a participação proporcional dos suicídios. ${ }^{8}$ Como indica a Figura 6, existe uma compensação a longo prazo nos valores para homicídios e para 
Figura 6

Porcentagem de homicídios e outras violências não definidas no total das causas extemas

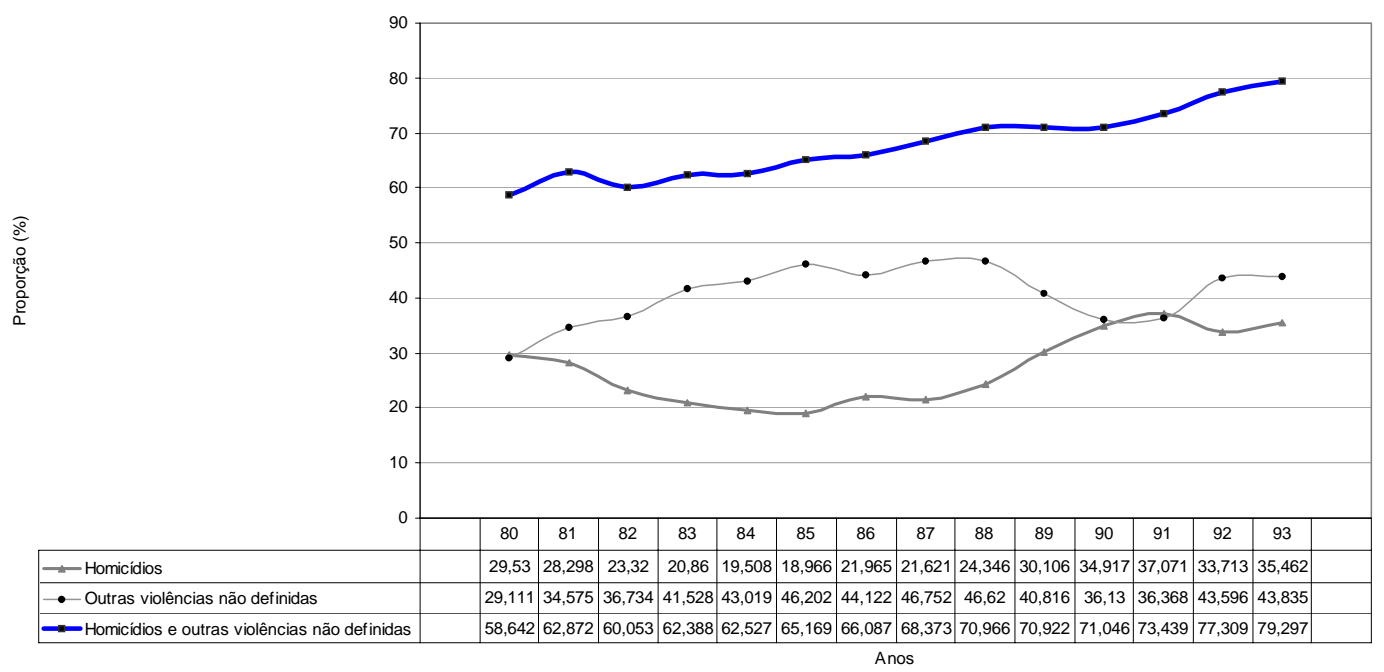

Figura 7

Número de óbitos por homicídios e outras violências não definidas e número de óbitos por acidentes de transporte - Homens. Região Metropolitana do Rio de Janeiro, 1980-1993

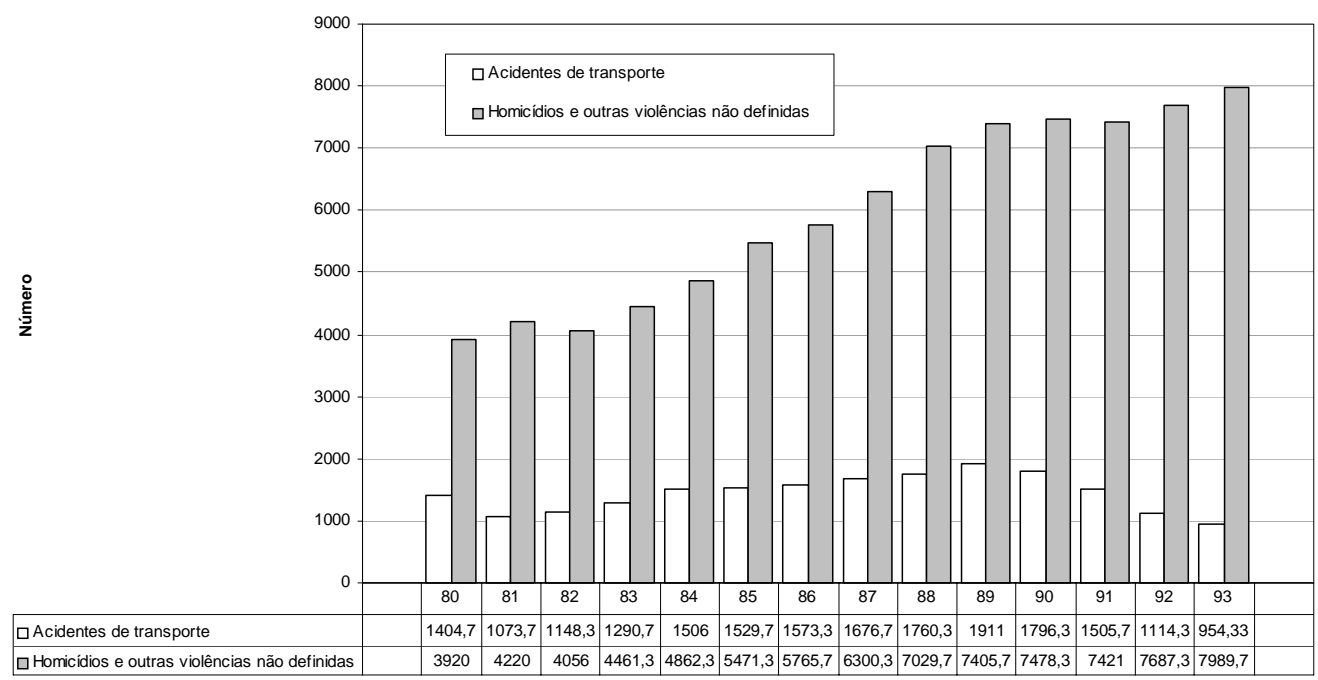

Anos

outras formas não definidas de violência. 0 crescimento constante nos valores adicionados desde 1980 (20,7 pontos percentuais) para a RMRJ é muito semelhante ao resultado encontrado na área metropolitana de Recife (César e Rodrigues, 1996): 22,3\% de 1979 a 1981. Em Recife também foi observado um crescimento constante na proporção de homicídios e um decréscimo constante em mortes causadas por outras formas de violência. Ao mesmo tempo, em Recife a mortalidade proporcional devida a acidentes com veículos motorizados diminuiu de $40,7 \%$ para $38,4 \%$ do total das mortes por causas externas. Uma situação semelhante é observada na RMRJ (Figura 7).

Além disso, o índice de mortalidade por causas violentas aumentou na RMRJ em 1991, com um máximo de 324,8 por 100 mil habitantes para homens do grupo etário 15-24 anos e 302,5 
Figura 8

Região Metropolitana do Rio de Janeiro, 1980-1991

Taxas de mortalidade

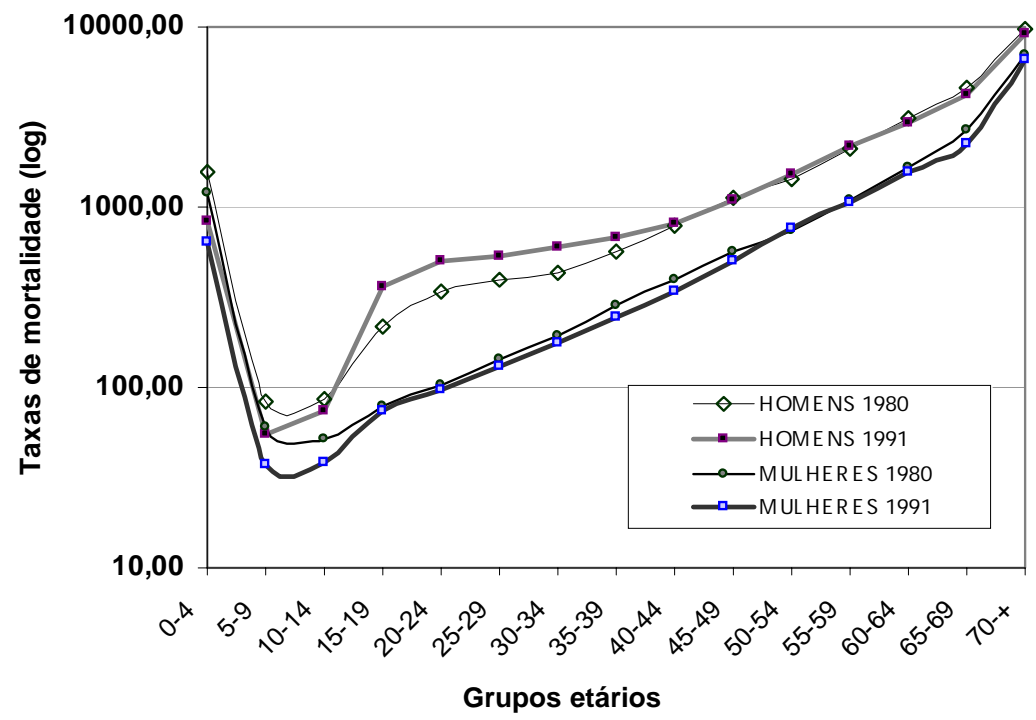

por 100 mil habitantes para o grupo etário 25-34 anos. As taxas de homicídio para o mesmo ano e mesmos grupos atingiram valores de 299,2 e 267 por cada 100 mil habitantes. Os dados utilizados para as mortes violentas são os das estatísticas vitais (FIBGE), e para homicídios, do SIM/Datasus. Ao compararmos essas duas fontes, observamos que os valores do SIM eram levemente inferiores aos valores do Registro Civil, mantendo, porém, a compatibilidade.

Se considerarmos separadamente o Município do Rio de Janeiro, os valores para mortes violentas em 1991 para os homens dos mesmos grupos etários são mais elevados do que os da RMRJ. Eles são de 358,8 para o grupo etário de 1524 anos e 308,3 por 100 mil habitantes para o grupo de 25-34 anos. Uma comparação entre os municípios do Rio de Janeiro e Buenos Aires, na Argentina, mostra valores muito mais baixos para Buenos Aires, com uma "barriga" no grupo de 25-34 anos: 59,3 por 100 mil habitantes. ${ }^{9}$

\section{A mudança das curvas de mortalidade da RMRJ e da RMSP}

A esperança de vida da população brasileira subiu de 41 anos em 1935 para 65 anos em 1991.
Mas, na última década, observa-se que o diferencial na esperança de vida por gênero cresceu, apresentando valores de 69,8 para as mulheres e 61,1 para os homens (Beltrão et al., 1996). Observa-se ainda que as curvas de mortalidade sofreram grandes mudanças de forma pela influência de vários fatores.

Durante os anos 80, a mortalidade na RMRJ e na RMSP cresceu entre os homens de quase todos os grupos etários, o que contrasta com a sua diminuição para as mulheres de todas as idades. A mudança mais importante no caso dos homens tem sido o destaque de uma "barriga de causas externas" para o grupo etário de 15-34 anos. Esse efeito também pode ser notado na mortalidade feminina, mas está limitado à redução ou cancelamento da melhora das taxas de mortalidade para os mesmos grupos de idade (Figura 8). ${ }^{10}$

A mesma situação, porém em níveis inferiores, pode ser observada nas curvas de mortalidade da Região Sul. Nesse caso, o contraste é mais evidente para as mulheres, que experimentam uma diminuição nas taxas de mortalidade durante 0 período, em todos os grupos etários. 0 desenvolvimento da "barriga de causas externas" nas curvas de mortalidade dos homens ocorreu num ritmo 


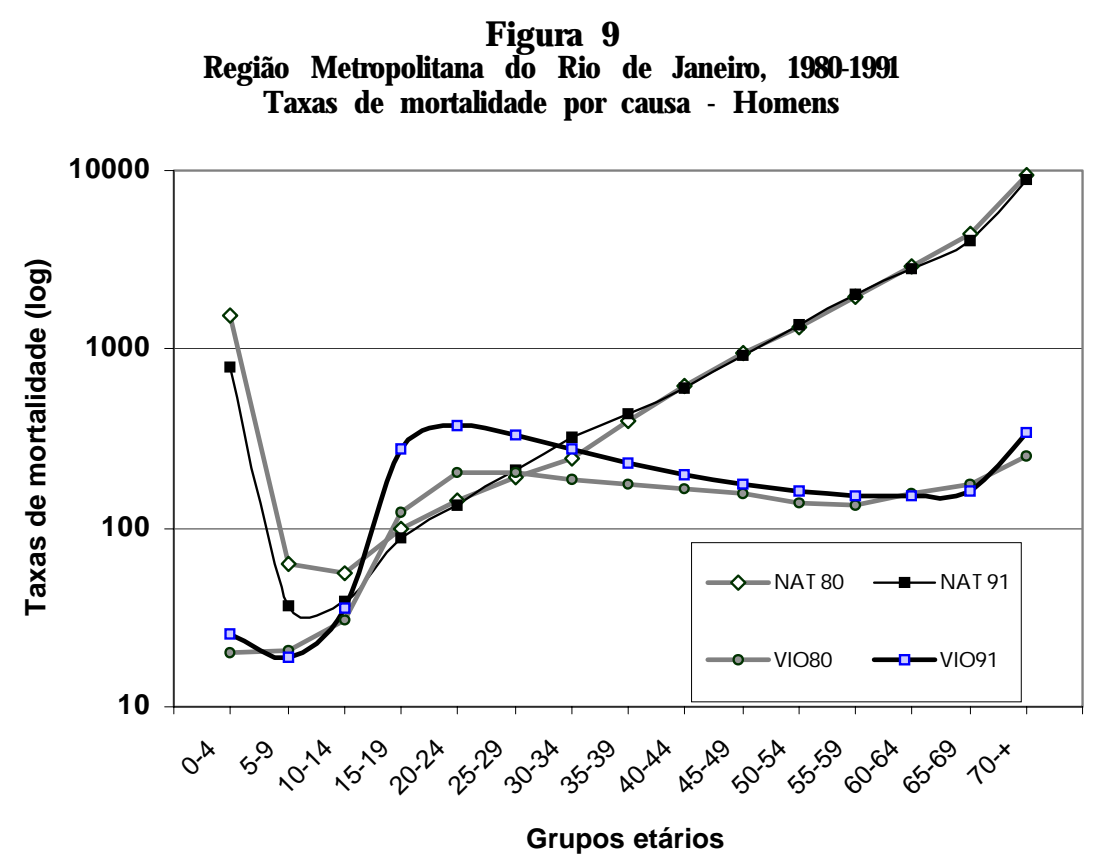

mais lento. Assim sendo, as mudanças na curva masculina denotam uma estagnação, ao invés de uma deterioração, nos grupos etários de 15-34 anos e uma pequena melhora nos outros grupos. $\mathrm{Na}$ Figura 9, os índices de mortalidade para os homens foram apresentados para causas naturais e violentas por grupos etários. Na RMRJ observamos um crescimento das taxas de mortalidade em todos os grupos etários, com exceção do grupo de 0-14 anos. Mais notável, porém, é o aumento dos índices de mortalidade na RMSP no grupo de 20-44 anos, um resultado que é consistente com as mortes relacionadas à AIDS.

Com algumas causas de morte importantes influenciando os índices de mortalidade, como mortes violentas e AIDS, podemos ficar tentados, como Pollard (1996), a adotar previsões mais conservadoras para o futuro. Mas, como argumenta esse autor, aqueles que adotaram previsões conservadoras no passado foram geralmente considerados, mais tarde, cautelosos demais. Infelizmente, as projeções atuais podem gerar resultados que mostrem uma deterioração ainda maior das taxas de mortalidade adulta nas áreas metropolitanas do Brasil.

\section{Discussão}

É certamente complexo analisar os fatores subjacentes aos processos de mudança nos padrões de mortalidade a partir de fenômenos socioeconômicos. No entanto, depois de determinar a magnitude dos anos de vida perdidos na Região Metropolitana do Rio de Janeiro e compará-la à da Região Metropolitana de São Paulo e outras regiões geográficas do Brasil, podemos considerar algumas características específicas da estrutura de relações sociais no Brasil que entendemos estar relacionadas aos índices de violência persistentemente altos verificados na sociedade brasileira. Nossos resultados mostraram um crescimento das mortes violentas nos grupos etários de 15-24 anos e 25-29 anos entre 1980 e 1991, o que é consistente com as tendências internacionais.

Em primeiro lugar, devemos considerar a questão das causas imediatas e específicas e dos fatores subjacentes aos precursores imediatos da violência. De maneira geral, é reconhecido (CDC, 1994) que, no presente, as causas específicas e imediatas desse problema continuam incertas. 0 aumento na ocorrência de homicídios pode ser 0 resultado do recrutamento de jovens, principalmente das classes média e baixa, pelo mercado de 
drogas, do uso de armas de fogo nesses mercados e da conseqüente distribuição de armas para outros jovens da comunidade. Isso, em retorno, pode resultar em um uso mais freqüente de armas para resolver conflitos (Blumstein, 1994).

Existe uma controvérsia em relação tanto às causas imediatas e específicas da violência, quanto aos fatores subjacentes a estas causas. Uma posição (Reiss e Roth, 1993; NCIPC e CD C, 1989) argumenta que os fatores subjacentes aos precursores imediatos da violência devam incluir a pobreza, as oportunidades educacionais e econômicas inadequadas ou inexistentes, a instabilidade social e familiar e a freqüente exposição individual à violência como uma forma aceitável de resolver desavenças. Outro ponto de vista, enfatizado no Brasil desde Coelho (1988, p. 151), afirma que a evidência empírica disponível não oferece apoio à hipótese de que 0 desemprego, a pobreza e a crise econômica estejam relacionados, em nível causal, aos índices de criminalidade.

Novamente é necessário cautela, pois nenhum fator isolado ou soma mecânica de fatores poderá explicar um fenômeno social complexo como a violência na sociedade brasileira. Antes de aceitar qualquer explicação, devemos identificar e examinar as diversas características do problema da violência no Brasil, que podem ser responsáveis por uma parcela substantiva das especificidades brasileiras. 0 objetivo deste trabalho é contribuir com um estudo interdisciplinar que almeja, como objetivo final, modelar uma explicação para esse complexo fenômeno, que poderá ter utilidade no desenvolvimento e na avaliação de diferentes alternativas de políticas sociais.

Sustentamos que, como primeiro passo para compreender a dinâmica das transformações sociais e demográficas relacionadas ao fenômeno da violência na sociedade brasileira, devemos examinar diversas características específicas da estrutura social do país, com vistas a construir uma "fenomenologia densa" (Elster, 1990). As características escolhidas podem ser consideradas fenômenostema: conceitos produzidos por processos de abstração que se debruçam sobre áreas de significado da estrutura social. Acontece que a sociedade, como produto humano, constrói e reformula per- manentemente essas características e suas interrelações.

Essas características, que identificamos inicialmente como específicas, são a impunidade, a fragilidade do sistema de justiça criminal, a corrupção nos órgãos estatais, o uso de força letal pela polícia, a emergência de cidades defensivas e de cidadãos defensivos, o vigilantismo, as chacinas e linchamentos, a "onda jovem" como mobilizadora da dinâmica demográfica e o papel da mídia como integradora de âmbitos de significado. Além disso, esses fatores devem ser colocados contra 0 pano de fundo das extremas desigualdades sociais da sociedade brasileira, desigualdades que apontam para as limitações do processo de democratização política do país. Essa lista não deixa de ser controversa, mas tentaremos nos manter o mais próximo possível dos fatos. Também a análise será limitada pelo espaço disponível para a exposição, e será necessariamente incompleta porque seria impossível analisar também aqui o significado da corrupção ou 0 papel da mídia em relação à violência. ${ }^{11}$

Vamos começar com a impunidade, que acreditamos ser, pela sua relevância, uma característica que assume formas específicas na sociedade brasileira. A impunidade no Brasil é marcada por uma resiliência extremada, mesmo nos casos em que a pressão da sociedade civil leva a algum tipo de penalidade, que geralmente é limitada em suas conseqüências. Essa resiliência na impunidade pode ser detectada não apenas nos níveis políticos e econômicos mais elevados, ${ }^{12}$ mas também em crimes como o tráfico de drogas, o jogo do bicho e as chacinas supostamente cometidas pela polícia. ${ }^{13}$

Uma segunda característica marcante é a fragilidade do sistema de justiça criminal brasileiro. Junto com a impunidade, esta fragilidade, como já foi notado (Adorno, 1992), gera uma baixa proporção de prisioneiros sentenciados. Como Adorno observa em relação à RMSP em 1992, "de um total de 4.274 prisioneiros acusados por crimes contra a pessoa, $33 \%$ foram sentenciados. No caso de crimes contra a propriedade, essa proporção é ainda menor [...] apenas 28\% foram sentenciados". Essa situação verifica-se em todos os estados da Federação.

Além da impunidade e fragilidade do sistema judiciário, e diretamente relacionada a essa situa- 
ção, a corrupção relacionada com a violência tem crescido desde os anos 70, como conseqüência do desenvolvimento do tráfico de drogas, que oferece oportunidades de lucros elevados não só no próprio negócio das drogas como também no tráfico de armas de fogo e na lavagem do dinheiro. A extorsão de traficantes pela polícia tornou-se uma situação comum, a ponto de a própria polícia da RMRJ reconhecer a existência na instituição de uma chamada "banda podre", que auferiria altos lucros com a extorsão e outros sérios delitos. A corrupção existe não apenas dentro da polícia, mas também no sistema judiciário e em praticamente todos os órgãos burocráticos. A expressão "montar um esquema" faz parte da linguagem comum, como sinônimo de corrupção.

Também há o uso de força letal pela polícia. A proporção extremamente baixa de prisioneiros sentenciados, determinada pelas razões examinadas acima, também é um ponto importante porque tem a violência como conseqüência: como o crime é uma ocupação sem altos riscos, graças à corrupção da Polícia Civil e à ineficiência do sistema de justiça criminal, é inútil encarcerar um homicida. Assim sendo, a punição é freqüentemente aplicada pela Polícia Militar sob a forma de pena capital, mediante o uso de força letal. A sabedoria popular de que "ladrão tem de morrer mesmo" assume o valor de uma crença que é compartilhada por amplos setores da população, independente de classe social, e é talvez um dos mais perversos resultados da falência atual do sistema de justiça criminal. Um setor da mídia tem transformado essa noção em uma apelação sistemática na captação do receptor. Um conceito tão fundamental quanto a idéia de que devemos olhar além da sentença e da correção e examinar o papel do sistema judiciário como parte integrante da educação, prevenção e tratamento é ainda impensável no Brasil.

Deve ser salientada, ainda, a mudança no padrão dos homicídios. Em 30 anos, o padrão de homicídios no Brasil se tem transformado dramaticamente. ${ }^{14}$ Complexas redes criminosas, com organização empresarial e conexões importantes, tanto nacionais quanto internacionais, não controlavam 0 tráfico de drogas nos anos 60. O comércio de drogas e armamento pesado, produtos e instala- ções químicas, tem adquirido padrões complexos, envolvendo a lavagem de dinheiro e extensiva corrupção de órgãos governamentais. O homicídio, que no Brasil de 30 anos atrás estava mais associado a causas passionais (Coelho, 1988), hoje em dia tende a estar também associado aos conflitos entre gangues de traficantes, às atividades clandestinas dos esquadrões da morte ou "polícias mineiras" e "justiceiros". Mas, como vimos, está também associado ao uso de força letal pelas PMs de vários estados, particularmente do Rio de Janeiro e São Paulo (Pinheiro et al., 1991). Estes elementos devem ser incorporados à análise dos homicídios tanto quanto os dados sobre a violência exercida em situações de lazer (bares, geralmente da periferia das áreas metropolitanas, bailes etc.), violência que atinge, como atores e vítimas, os indivíduos das camadas mais carentes da população.

São precisamente os pobres das periferias os que convivem com o risco das chacinas e dos homicídios no fim de semana. Segundo os dados do Departamento de Homicídios e Proteção à Pessoa (DHPP) da Secretaria de Segurança Pública de São Paulo, 50\% dos homicídios acontecem no fim de semana, "[... ] a maioria por motivos fúteis, como brigas de bar ou desentendimentos entre vizinhos. Em seguida aparece o tráfico de drogas, e logo a seguir a vingança e 0 enfrentamento entre quadrilhas e membros de uma mesma quadrilha por desentendimentos na partilha" (Folha de S. Paulo, 24/3/1998, pp. 3-6). Vale a pena citar as declarações do delegado Marco Antônio Desgualdo, diretor do DHPP:

Muitos homicídios são cometidos por pessoas de bem, sem passagem pela polícia, que se desentendem com alguém em um bar e acabam atirando. Se elas não estivessem armadas, esses crimes não aconteceriam. A pessoa está desempregada, com a família passando fome, sofrendo uma enorme pressão social. Quando ela bebe, essa tensão aflora e um pisão no pé pode ser suficiente para ela acabar cometendo um crime. ${ }^{15}$

As "pessoas de bem" são muitas vezes protagonistas, em papéis diferentes, tanto das chacinas como dos homicídios, e, segundo as estatísticas, 
matam e morrem pelos mesmos motivos fúteis. Estes motivos fúteis são transformados pelo contexto em motivos socialmente relevantes: os dados da vigilância epidemiológica e da polícia confirmam que os maiores valores absolutos e a tendência à escalada ocorrem nas periferias das áreas metropolitanas do Rio de Janeiro e de São Paulo. ${ }^{16}$ E estas periferias caraterizam-se por ter experimentado, em muitos distritos, um grande crescimento populacional em áreas distantes e sem qualquer infraestrutura, onde a pobreza é generalizada, 0 analfabetismo duplica ou triplica os valores médios da região, não há perspectivas de mobilidade social e a homogeneidade social está baseada na exclusão de todos. Nas periferias pobres, os investimentos públicos são insuficientes, faltam escolas de primeiro e segundo graus e as existentes são muitas vezes de péssima qualidade e sempre sujeitas ao vandalismo, os hospitais estão afastados do bairro, não há saneamento básico ou este é muito deficiente, não há creches e geralmente as opções de lazer estão limitadas aos bares da região. Finalmente, 0 trabalho está sempre a muitas horas de ônibus do local da residência: "Aqui só tem trabalho de ajudante em loja de material de construção" (Folha de S. Paulo, 4/ 1/1998, pp. 3-7). Perspectiva de mobilidade social, só para os donos das lojas.

Uma observação mais atenta aos padrões de violência originados da percepção de um sistema de justiça criminal corrupto, indigno de confiança, lento e injusto, revelará fenômenos tais como os justiceiros e os esquadrões da morte. Existem também organizações de pistoleiros contratados por pequenos comerciantes e companhias de transporte público nas periferias de muitas cidades brasileiras para controlar a criminalidade, matando ladrões e até grupos que se recusam a pagar pelo transporte ou simplesmente perturbam a ordem nas áreas onde tais comerciantes ou companhias de transporte operam. Às vezes o assassinato é cometido por seguranças privados desses empresários, agindo não como justiceiros profissionais, mas simplesmente "fazendo um bom trabalho" na área. ${ }^{17} \mathrm{Em}$ conseqüência dessas atividades, a imprensa atualmente mantém estatísticas sobre 0 número de chacinas na RMSP. Essas chacinas produzem múltiplas vítimas, freqüentemente relacionadas umas às outras, com a óbvia intenção de eliminar testemunhas. A maior parte desses crimes nunca é resolvida e ninguém é punido por eles. ${ }^{18}$

Se nessas áreas metropolitanas as chacinas envolvem uma média de três a quatro vítimas por chacina, outros massacres adquirem importância nacional devido a um número muito mais elevado de vítimas envolvidas. Alguns destes foram denunciadas no exterior. Nos últimos seis anos, oito grandes chacinas aconteceram no Brasil, com mais de 200 mortes. $^{19}$

Um panorama das características da violência no Brasil deve também levar em consideração os linchamentos. Nesta década, o linchamento é outro fenômeno brasileiro sobre o qual existe uma convergência entre 0 ponto de vista das PMs sobre 0 uso de força letal e explicações populares exacerbadas sobre a impunidade de criminosos (incluindo mortes causadas pela polícia) e a inutilidade tanto da polícia quanto do sistema judiciário. A vingança das populações vítimas do crime e que não têm esperança de obter justiça e compensação por parte da polícia e do sistema judiciário é apresentada muitas vezes na mídia como um ato espontâneo. Na realidade, na maior parte dos casos existe uma estrutura oculta organizando os linchamentos (Martins, 1989; Pinheiro, 1991). Entre 1979 e 1989, como mostra Martins (1989), houve 272 linchamentos, metade deles ocorridos após o fim do regime militar. $^{20}$

\section{A emergência das cidades defensivas e dos cidadãos defensivos}

Nos anos 60 e 70, quando se notou que 0 crime violento nos Estados Unidos crescia num ritmo considerado alarmante para os padrões americanos de então, foram exploradas (Gold, 1970) as relações entre o desenho urbano e o controle e prevenção da violência. Naquele momento, interpretou-se que muitas das principais cidades americanas estavam sendo fortificadas, e a hipótese de cidades defensivas aparecia como uma possibilidade concreta, com todas as suas conseqüências destrutivas da sociabilidade.

A idéia de cidades defensivas estava muito relacionada ao conceito sociológico de subculturas 
urbanas violentas. ${ }^{21}$ As subculturas, no caso dos Estados Unidos, foram interpretadas como fenômenos urbanos originados em bairros racialmente segregados e economicamente carentes, habitados por indivíduos que não eram criminosos "profissionais" que minimizam os riscos, e sim "jovens irados que não acreditam na sociedade" (Gold, 1970). Esses jovens tinham aspirações consumistas semelhantes àquelas do resto da sociedade, mas valores e atitudes diferentes e uma economia de subsistência e lucro financeiro diferenciados, possíveis devido às características específicas da vida desses grupos de jovens nas cidades norte-americanas da década de 70. 0 tráfico de drogas cresceu aumentando fortemente as possibilidades de lucros financeiros imediatos, em sinergia com a percepção da violência como um comportamento normal, necessário à sobrevivência no competitivo mercado das drogas.

Cidades defensivas e subculturas produziram cidadãos defensivos. Esse fenômeno, com características semelhantes, pôde também ser notado no Brasil. No caso dos ricos, ampliou-se o uso de guardas de segurança privados e de procedimentos e regulamentos privados para resolver questões de segurança em áreas específicas (bairros afluentes, condomínios de casas ou apartamentos de luxo ou de classe média etc.). Ao mesmo tempo, nas áreas carentes e periféricas das regiões metropolitanas, houve um crescimento das atividades dos "justiceiros" e do ato de desespero extremo e vingativo de linchamento. Desta forma, o índice de homicídios numa mesma região metropolitana oscilará fortemente quando se consideram áreas geográfica e socialmente distantes, sob diferentes condições de controle da criminalidade. As chances de morrer assassinado também fazem uma clara distinção entre os protegidos e os socialmente excluídos. Há toda uma gradação de áreas de risco que inclui, na Região Metropolitana de São Paulo, desde bairros com taxas de homicídios muito baixas, quase "européias” (Consolação, Perdizes, Jardim Paulista etc.), até uma faixa de regiões de altíssimo risco (Brasilândia, Jardim Ângela Guaianazes, Capão Redondo, e 0 próprio centro de São Paulo, Sé). A média das taxas de homicídio por 100 mil habitantes das cinco regiões mais violentas de São Paulo é de 84,4; a média das cinco menos violentas, 5,3, ou seja, 16 vezes menor. Isto implica patamares de violência qualitativamente diferentes, e condições de vida e possibilidades de sociabilidade também qualitativamente diferentes. ${ }^{22}$

\section{Desigualdades extremas: a persistência dos "dois Brasis"}

Finalmente, o pano de fundo. As diferenças entre Perdizes e Jardim Ângela não são um caso isolado. Elas revelam uma contínua oposição entre dois Brasis. Existem no país condições sociais que expressam desigualdades extremas. De acordo com os valores do Programa para o Desenvolvimento das Nações Unidas (1992), a renda dos 20\% mais ricos da população brasileira era então 26 vezes maior que a renda dos 20\% mais pobres. Em 1991, 0 Brasil tinha a pior distribuição de renda de todos os países com mais de dez milhões de habitantes. Nos anos 80, na chamada "década perdida", o PIB per capita do Brasil baixou 4\%. A população abaixo da linha de pobreza (uma renda familiar mensal per capita abaixo de aproximadamente US\$35) chegou a 39 milhões, ou $27 \%$ da população, em 1990. Na RMSP, os pobres representam $6 \%$ da população, mas sua renda representa apenas $0,4 \%$ da renda metropolitana total. Na RMRJ os valores correspondentes são de 13\% e 1,4\%. Em ambas as regiões, a situação de miséria afeta tanto os imigrantes do Nordeste como os trabalhadores urbanos qualificados desempregados durante a recessão econômica. A renda pessoal dos trabalhadores urbanos qualificados do setor privado sofreu um decréscimo líquido de $31,7 \%$ entre 1979 e $1990 .{ }^{23}$ De acordo com os valores do Instituto Brasileiro de Geografia e Estatística (IBGE) para 1990, 32 milhões de crianças viviam com famílias que ganhavam mensalmente menos da metade de um salário mínimo (nos valores de hoje, aproximadamente US\$56). Essa situação não melhorou: o Relatório sobre Desenvolvimento Humano da Nações Unidas, editado pelas Nações Unidas em 1996, coloca o Brasil na 63a posição mundial. Esse contexto social deve fazer parte de qualquer modelo explicativo, porque diz respeito a critérios e políticas de alocação de recursos. Como estes nunca existem em quantidade e qualidade suficientes para 
as áreas mais carentes, acaba-se perpetuando ou aprofundando a disparidade de situações.

\section{Descontinuidades demográficas e a "onda jovem" nos anos 90}

A "onda jovem" (Bercovich e Madeira, 1990) acontece quando, como resultado de uma dinâmica demográfica prévia, os grupos etários entre 15 e 24 anos experimentam um crescimento excepcional. Este alongamento, à medida que cresce na pirâmide populacional, gera exigências que 0 governo deve enfrentar com políticas específicas. No Brasil, este fenômeno está acontecendo nos anos 90. O resultado dessa tendência é a concentração de jovens nas áreas periféricas carentes das regiões metropolitanas. No ano 2000, o grupo etário de 15-19 anos será muito maior do que nos anos precedentes. Isso significa acesso insuficiente aos recursos sociais, baixos níveis de instrução e qualificação para 0 trabalho, uma interrupção precoce da adolescência e, como vimos, um risco maior de sofrer uma morte violenta. Além disso, mais da metade desses jovens pertence a famílias com uma renda familiar menor que 0 salário mínimo (Fundação SEADE, 1994). Esse fato tem implicações e levanta complexas questões socioeconômicas relacionadas a diversos problemas que precisam ser discutidos (juventude e pobreza, juventude e educação e oportunidades de trabalho, jovens como consumidores, drogas e juventude, gangues e juventude, juventude e 0 uso de armas de fogo, jovens como perpetradores, jovens como vítimas).

Essas questões exigem sérios esforços para educar e afastar jovens e pré-adolescentes da violência, mas esses objetivos requerem o estabelecimento de um novo quadro de prioridades econômicas, enfocando a saúde, a educação e 0 trabalho, objetivos que parecem ir em direção oposta às políticas econômicas brasileiras atuais.

Uma abordagem desta questão explora a relação entre 0 peso relativo da população jovem e 0 potencial de tensão na sociedade. Wriggings (1988) aponta diversos possíveis fatores subjacentes aos movimentos jovens radicais: um mercado de trabalho cada vez menor; oportunidades limita- das de obter a educação requerida por um mercado de trabalho com exigências de preparo tecnológico cada vez maiores; perda de confiança no sistema político e nos líderes políticos; percepção de uma corrupção disseminada etc. No caso do Brasil, o potencial para a tensão social também está localizado nos grupos de jovens (15-24 anos), excepcionalmente numerosos no presente.

\section{Implicações da pesquisa e observação}

Se no passado as políticas de saúde pública no Brasil lidavam essencialmente com doenças infecciosas, que representavam o mais importante grupo de doenças que contribuíam para a taxa de mortalidade total, as mudanças nos padrões da mortalidade demonstram, no presente, uma importância cada vez maior das chamadas doenças sociais, que incluem causas externas como acidentes e homicídios. A violência constitui hoje um problema de saúde pública, devido ao seu impacto na saúde e no bem-estar dos jovens. 0 enfoque demográfico é uma das abordagens científicas que pode colaborar para a compreensão do problema da violência no Brasil, ao pesquisar, entre outras, a dimensão geográfica de um fenômeno que varia muito entre as regiões. Pode também contribuir para 0 debate sobre as mudanças nos índices de mortalidade $\mathrm{e}$ violência e ajudar a determinar que medidas podem efetivamente prevenir a violência.

Uma vez que a violência é considerada um problema de saúde pública, parece existir um acordo sobre a necessidade de:

a) descrição do problema, o que inclui coleta e análise dos dados disponíveis, tendências e projeções em áreas definidas. Esses dados devem incluir as características, a distribuição e as tendências da população alvo, com indicadores que possam medir, além da morbilidade e mortalidade, as características e tendências sociais, econômicas, políticas e do meio ambiente;

b) identificação dos fatores de risco e de proteção, com a desagregação desses fatores por área e parâmetros demográficos das diferentes populações;

c) elaboração de objetivos e estratégias para alcançar metas específicas; 
d) seleção, priorização e implementação de estratégias, incluindo a implementação de programas promissores no âmbito das comunidades;

e) monitoramento dos programas criados para combater a violência.

A pobreza, a discriminação e a falta de oportunidades para a educação e o emprego constituem importantes fatores de risco e devem ser abordados como parte de qualquer solução para o problema da violência entre jovens. Um conhecimento mais vasto e abrangente das características sociais e econômicas da sociedade brasileira e da dinâmica de suas mudanças constitui parte importante dessa abordagem.

Estratégias para a redução da violência devem também começar cedo na vida, antes que os jovens adotem idéias e práticas violentas e vícios de comportamento na resolução de conflitos. Embora as estratégias mais eficazes para prevenir a violência nos jovens não tenham sido determinadas, esforços no sentido de prevenir esse problema devem empregar princípios estabelecidos de promoção da saúde e enfatizar o uso de múltiplas medidas de intervenção complementar (Mercy et al., 1993; Green e Kreuter, 1991): ou seja, estamos falando de políticas públicas multisetoriais de longo alcance.

A demografia e as ciências sociais têm um papel importante em qualquer tentativa de solução destes problemas no Brasil, pois fornecem a informação necessária para a sua abordagem no âmbito da saúde pública. Sua contribuição inclui: coleta e análise de dados; preparação de resumos de monitoramento sobre acidentes de trânsito, homicídios, suicídios e mortalidade causada por uso de armas de fogo no Brasil; pesquisa sobre fatores de risco e proteção; treinamento; desenvolvimento da consciência pública dos problemas e soluções; e avaliação dos projetos específicos de intervenção sobre a violência entre os jovens (CDC, 1994).

Sabemos pouco sobre as razões dessas mudanças que estão ocorrendo. Mediante 0 desenvolvimento de uma análise demográfica de dados poderemos avançar além da proposta de Da Matta $(1982)^{24}$ de uma oposição entre espaços públicos e privados, ou da afirmação de que a violência criminal no Brasil é primariamente um problema de possessão do corpo, dentro da tradição escravocra- ta de Calegaris (1996). Embora tais pontos de vista possam ser válidos em áreas restritas de conhecimento, não podemos esperar muita ajuda deles no sentido de estabelecer objetivos ou uma ação; a magnitude do problema parece indicar que o trabalho orientado no sentido de pensar políticas públicas é de uma urgência incontestável.

\section{Violência, demografia e direitos civis}

No início da década de 80, o segundo encontro do Grupo de Peritos em Populações e Direitos Civis das Nações Unidas (Viena, 1981) já discutia as implicações sobre os direitos civis decorrentes da persistência de taxas elevadas de mortalidade em subpopulações vulneráveis e, em países em desenvolvimento, da possibilidade real de uma discriminação que poderia afetar algumas coortes jovens, de tamanhos excepcionalmente grandes, que apresentam freqüentemente problemas sociais e de políticas públicas de difícil solução para o Estado. A discontinuidade no tamanho de coortes específicas (Bercovich e Madeira, 1990) levanta, já no presente, sérios problemas no que se refere à alocação de recursos públicos escassos. Cabe esperar que este processo se aprofunde no futuro, quando os jovens serão convocados a suportar o ônus dos custos sociais de coortes de maior idade cada vez mais numerosas.

0 processo de democratização no Brasil devolveu os direitos civis e políticos aos cidadãos, mas no mundo real sabemos que é muito difícil definir uma distinção clara entre direitos civis, políticos e socioeconômicos. Tendo observado as condições de extrema desigualdade social e as características específicas do fenômeno da violência no Brasil, lembramos que a ação afirmativa em relação aos direitos humanos não é simplesmente uma questão de incentivar a ação do governo no que diz respeito a indivíduos ou grupos especialmente prejudicados, mas também implica desenvolver uma pesquisa orientada para a ação e para a análise de políticas públicas. Inclui também a apresentação de propostas ao governo para lidar com situações de violência que infrinjam os direitos dos indivíduos ou grupos sociais. Uma vez que essas metas estejam sendo alcançadas, talvez o discurso do presidente Fernan- 
do Henrique Cardoso ${ }^{25}$ argumentando que atualmente, no Brasil, mais do que adquirir bens de consumo anteriormente inacessíveis, os cidadãos estão usando seus direitos civis, seja mais do que uma mera retórica de validade conjuntural para grandes segmentos da população.

Como foi mostrado aqui, em situações em que a luta contra as desigualdades está em jogo (Farley, 1988), muitas questões que a ação suscita não podem ser respondidas apenas com dados demográficos, porque elas dependem de nossas idéias em relação ao que é justo e igualitário. Mas os interesses do governo relacionados a essas questões e a programas específicos podem ser avaliados baseando-se em suas conseqüências. Contribuir ao debate sobre o problema da violência no Brasil, e sobre objetivos e estratégias das políticas sociais e de segurança, constitui um desafio para os cientistas sociais e os demógrafos envolvidos na pesquisa interdisciplinar.

\section{NOTAS}

1 Neste ponto, como o leitor já terá percebido, estamos seguindo tanto 0 Durkheim de A s regras do método sociológico (1988) como Berger e Luckmann (1989) de A construção social da realidade. Veja também Elster (1990).

2 A Classificação Internacional de Doenças (CID) é coordenada pela Organização Mundial da Saúde (OMS) e tem uma aceitação praticamente mundial. Dentro da classificação estão os denominados "Códigos E", correspondentes ao grupo das denominadas "causas externas” (E 800-E999). Estão incluídos os homicídios e lesões intencionalmente infligidas sob os códigos E960-E969. Existe uma importante bibliografia que discute as virtudes e problemas desta classificação, discussão que se associa com o problema da subenumeração dos homicídios. Ver Mello Jorge (1988), Minayo (1994), Lopes (1994) e Bercovich et al. (1998).

3 Como resultado deste procedimento, padrão nas análises demográficas, aparecem resultados fracionários no número de óbitos.

4 Neste ponto, o Brasil compartilha um fenômeno que tem caraterísticas mundiais: 0 aparecimento de diferentes "ondas jovens".

5 Chamada nos Estados Unidos de eco do "baby boom".

6 Em 1991, a população da área metropolitana do Rio de Janeiro era de 9.814.574 habitantes e a população da área metropolitana de São Paulo somava 15.145.410 habitantes. Cf. FIBGE, Censo Demográfico de 1991.

7 A Tabela 1 lista somente os municípios incluídos neste estudo. Atualmente, a composição da área metropolitana está levemente modificada, devido à criação de novos municípios por subdivisão dos antigos.

8 Entre as razões para esta subestimação dos dados de homicídios, Lopes (1994) destaca o preenchimento incorreto ou incompleto do formulário da certidão de óbito. 0 campo 37, que descreve as causas externas de morte, é preenchido corretamente em somente 31\% dos formulários. Lopes acredita que isso ocorra porque 0 médico encarregado não está ciente da importância desse campo. Nossa própria experiência indica que a razão para isso pode estar em o funcionário não querer se envolver com procedimentos judiciais que se iniciam automaticamente diante do atestado de homicídio. Outra razão para a subestimação, embora sua relevância seja pequena, pode ser a existência de cemitérios clandestinos e as falsas afirmações da causa mortis. Podemos incluir razões políticas nesta subestimação de homicídios. Para uma discussão da qualidade dos dados de mortalidade no Brasil ver Vasconcelos (1996).

9 Os números são também altos para Recife (César e Rodrigues, 1996). No período 1989-91, os valores para 0 sexo masculino na faixa etária entre 20 e 49 anos foram de 430,37 para causas violentas e de 258,8 para homicídios, por 100 mil habitantes.

10 A crescente proeminência da "barriga de causas externas" entre homens jovens tem sido maior, em termos relativos, na RMSP, quando comparada à RMRJ. Essa maior deterioração na RMSP é associada a uma combinação de causas externas e mortes relacionadas à AIDS no grupo etário de 25-40 anos (ver Ferreira e Castinheiras, 1996; Waldvogel, 1992; Camargo, 1996; Mello Jorge, 1998).

11 Para uma análise de processos na estrutura social que inter-relacionam corrupção e violência, ver Bercovich, Dellasoppa e Arriaga (1998).

12 Aqui podemos notar as conseqüências extremamente limitadas do impeachment do ex-presidente Fernando Collor de Mello e dos deputados e senadores envolvidos no chamado "escândalo do orçamento".

13 No caso das chacinas da Candelária, Vigário Geral e Acari, no Estado do Rio de Janeiro, os procedimentos judiciais, como de costume, desenrolaram-se de modo extremamente lento, levando a resultados dúbios, até mesmo após o pronunciamento de sentenças severas.

14 Nos Estados Unidos, as mudanças foram maiores para 0 sexo masculino na faixa etária de 15 a 19 anos, onde as taxas cresceram substancialmente.

15 Folha de S. Paulo, 24/3/ 1998, pp. 3-6. "Note-se que [...] se o álcool fosse a causa da violência apenas por fazer os indivíduos se comportarem mais agressivamente, a violência aconteceria por igual em todos os locais onde se bebe. De fato, na maioria dos locais onde se bebe álcool são raras as cenas de violência [...] Não se conhecem com precisão quais são as características de um local onde se 
vendem bebidas alcoólicas que o fazem perigoso em termos de violência, mas há evidência que sustenta diversas explicações. Pessoas que bebem em bares violentos podem se comportar violentamente de modo a 'enturmarse' ou a sustentar uma posição social, ou ainda a progredir socialmente. Pessoas com raiva ou frustração podem procurar estes bares porque acreditam que beber nestes locais implica uma permissão social para se comportar violentamente [...] As conexões entre bebida e violência têm sido identificadas pelos pesquisadores em muitos países com culturas predominantemente européias. Mas não têm sido encontradas em muitas outras culturas tribais e tradicionais, mesmo onde beber para alegrar o espírito é comum. Por razões desconhecidas, as expectativas de que a violência siga à bebida não têm se desenvolvido nestas culturas (Roth, 1994).

16 No caso de São Paulo, ver os dados do Programa de Aprimoramento das Informações sobre a Mortalidade (Pro-Aim) da Prefeitura de São Paulo.

17 Em fevereiro de 1997, cinco adolescentes foram mortos em Belford Roxo, um dos municípios da RMRJ, por um guarda de segurança de uma companhia de transportes privada, depois de terem se recusado a pagar pelo serviço (a passagem custa aproximadamente US\$ 0,70) e iniciado uma baderna no ônibus (Jornal do Brasil, 2324/2/ 1997). A privatização do espaço público e 0 controle da polícia privada encontram-se aqui expressos de uma forma extremada.

18 De janeiro a novembro de 1995, o SPMR registrou 163 homicídios em 48 chacinas; no mesmo período em 1996 foram registrados 162 homicídios em 46 chacinas (Folha de S. Paulo, 30/11/ 1996). Este jornal guarda a estatística de múltiplos assassinatos deste tipo.

19 Estas chacinas são: Acari (RMRJ, julho de 1990), Carandiru (Prisão de Carandiru, São Paulo, outubro de 1992), Candelária (Rio de Janeiro, junho de 1993), Vigário Geral (RMRJ, agosto de 1993), índios Yanomâmis em Roraima (agosto de 1993), Taquaril (Belo Horizonte, março de 1996) e Eldorado dos Carajás (Pará, abril de 1996).

20 Em Salvador, na Bahia, houve 26 linchamentos em 1988, 82 em 1989 e 112 em 1990. Nos três primeiros meses de 1991 houve 53, o que significa um em cada três dias (Pinheiro, 1991). Linchamentos continuam a acontecer em muitos lugares. Em julho de 1993, em Olaria, um bairro do Rio de Janeiro, três adolescentes suspeitos de serem ladrões foram perseguidos por uma multidão e espancados até a morte por duas horas e meia. Pouco tempo depois provou-se serem inocentes. A multidão foi instigada por quatro empregados de um bicheiro que controla o jogo do bicho na área. Existe um pacto de silêncio em Olaria: "Quem falar morre", foi a ordem do bicheiro (V eja, 14/ 7/ 1993). Como afirma Martins (1989), nesses linchamentos que ocorrem em capitais a classe pobre e trabalhadora manifesta sua vontade; ela está na posição de juiz, rendendo veredictos em relação a crimes aos quais está sujeita. Às vezes, como em Olaria, estes trabalhadores levam inocentes à morte, sob 0 comando de homens de segurança do jogo do bicho que só desejam "manter a área limpa".
21 Estas subculturas foram definidas como grupos da população que favorecem e aceitam a violência como um comportamento normal, e não como uma atividade ilícita. Os valores e as atitudes das subculturas são mais prevalecentes entre os homens da classe mais baixa dos afro-americanos, do fim da adolescência até 0 final da meia idade, vivendo em cidades centrais. Deixar de cometer violência, "de provar-se como homem", por exemplo, poderia mais provavelmente resultar no ostracismo social, embora nem todas as pessoas pertencentes às subculturas cometam violência em todas as situações (Gold, 1970).

22 Ver Cedec (1996 e 1997). No caso de São Paulo, é apresentado o "risco distrital" para o município segundo valores de população e óbitos por homicídios para 0 ano de 1995 (Tabela 1). Já no caso do Rio de Janeiro, os resultados apresentados na Tabela 1 (taxa estimada de homicídios para residentes de 15 a 34 anos, por bairro de residência, de janeiro a outubro de 1996) devem ser questionados tanto pelo fato de se ter utilizado a população residente de 15 a 34 anos correspondente ao Censo de 1991 junto com dados de homicídios de janeiro a outubro de 1996, como por não se ter realizado qualquer tratamento estatístico e agrupamentos que pudessem minimizar a instabilidade (reconhecida) das taxas calculadas. Além disso, utilizar os dados de população de 1991 implica ignorar a existência de uma "onda jovem" de forte impacto nos resultados demográficos.

23 Mede a renda, excluindo a agricultura. FIBGE, Tabulações especiais da PNAD, 1979, 1983, 1986 e 1990.

24 No Brasil, temos o mito do homem cordial, um homem que age com o coração com amigos e colegas semelhantes, um arquétipo que, juntamente com as desigualdades sociais, constitui um acessório fixo da Sociologia brasileira. Este modelo aparece várias vezes em diferentes explicações. Uma visão antropológica da violência (D a Matta, 1982) sustenta a existência de uma oposição entre dois espaços: casa e rua. Casa é o espaço privado, onde cada pessoa tem uma identidade de contornos definidos, com reconhecimento moral e pessoal. A rua é o espaço público, o espaço do ilimitado (ou indefinido), e (hipoteticamente) de identidades idênticas e anônimas, que requer o reconhecimento burocrático do Estado para preservar a condição de cidadão. 0 estabelecimento de redes sociais, para muitos brasileiros, tem ainda uma forte conotação de patrimonialismo, e as relações, em política e negócios, são marcadas por personalismo e patronagem.

25 Presidente Fernando Henrique Cardoso, "Uma revolução silenciosa", Folha de S. Paulo, 29/12/ 1996, p. 3. 


\section{BIBLIOGRAFIA}

AD ORNO, S. (1992), Criminal violence in modern Brazilian society: the case of the State of São Paulo. Trabalho apresentado na International Conference on Social Changes, Crime and Police, Budapeste, 1-4 de junho.

ARRIAGA, E. (1984), "Measuring and explaining the change of life expectancies". D emography, 21(1): $83-96$.

(ed.). (1993), Readings in population research methodology. $\mathrm{V}$ ol. 2: M ortality research. Chicago, United Nations Population Fund.

(1994), Population analysis with microcomputers. Washington, Bureau of the Census/ UNFPA.

(1996a), "Los años de vida perdidos: su utilización para medir el nivel y el cambio de la mortalidad". Notas de Población, Centro Latinoamericano de Demografia, Santiago, Chile, ano XXIV, 63: 7-38.

(1996b), "Comentarios sobre algunos indices para medir el nivel y el cambio de la mortalidad". E studios D emográficos y U rbanos, El Colegio de Mexico, 11, 1: 5-30.

BELTRÃO, K.I. et al. (1996), "Avaliação do padrão etário da mortalidade brasileira por sexo: 19791994". Como V ai? População Brasileira, Brasília, ano 1, 3: 1-6.

BERCOVICH, A., DELLASOPPA, E. e ARRIAGA, E. (1998), “'J'adjuste, mais je ne corrige pas': jovens, violência e demografia no Brasil. Algumas reflexões a partir dos indicadores de violência", in Comissão Nacional de População e D esenvolvimento, Jovens acontecendo na trilha das políticas públicas, Brasília, CNPD, pp. 293-359.

BERCOVICH, A. e MADEIRA, F. (1990), "D escontinuidades demográficas no Brasil e no Estado de São Paulo". A nais do V II E noontro $\mathrm{N}$ acional de Estudos Populacionais, ABEP.

BERGER, P. e LUCKMANN,T. (1989), L a construoción social de la realidad. Buenos Aires, Amorrortu Editores.

BLUMSTEIN, A. (1994), Youth violence, firearms and illicit drug markets. Working paper, Pittsburgh, Carnegie Mellon University.

BUARQUE de HOLLANDA, S. (1969), Raízes do Brasil. Rio de Janeiro, José Olympio.
CALEGARIS, C. (1996), "A praga escravagista brasileira". Folha de S. Paulo, 22/9/1996, Caderno Mais!, p. 5.

CAMARG O, A.B.M. (1996), Transiç̧ão epidemiológica no Brasil: evolução e novos fatos. Trabalho apresentado no Seminário sobre Previdência Social, Brasília.

CDC - Center for Disease Control. (1994), Morbidity and Mortality Weekly Report, 43, 40, 14 de outubro.

CEDEC. (1996), Mapa de risco da violência: Cidade de São Paulo. São Paulo, Cedec.

. (1997), Mapa de risco da violência: Cidade do Rio de Janeiro. São Paulo, Cedec.

CÉSAR, I.A. e ROD RIGUES, R.N. (1996), “A mortalidade por causas externas no Recife durante os anos 80: uma análise exploratória". A nais do X E noontro Nacional de Estudos Populacionais, ABEP, vol. 4: 2.053-2.072.

CIDE - Centro de Informações e Dados do Rio de Janeiro. (1995), A nuário estatístio do Rio de Janeiro. CD-ROM.

COELHO, E. Campos. (1978), "A criminalização da marginalidade e a marginalização da criminalidade". Revista de A dministracão Pública, 12, 2, abr.-jun.

(1988), "A criminalidade urbana violenta". D ados, Rio de Janeiro, Iuperj, 31, 2: 145184.

DA MATTA, R. (1982), A violência brasileira. São Paulo, Brasiliense.

DAS GUPTA, M. (1989), "The effects of discrimination on health and mortality". Proceedings of the International Population Conferenœ, vol. 3: 349-365

DELLASO PPA, E.E. (1991), "Reflexões sobre a violência, autoridade e autoritarismo". Revista USP, 9, mar.-mai.

(1995), "Violência, estrutura de relações sociais e interação: relações de conluio na sociedade brasileira". Série Estudos, Rio de Janeiro, Iuperj, 91: 41-54.

. (1997), Funkin' Rio: music, violence, and the socialization of the young wave. Trabalho apresentado à International Sociological Association (ISA), Research Committee 41 (Sociology of Population), Workshop on Population, Beijing, 11 de outubro. 
DELLASO PPA, E.E., BERCOVICH, A. e ARRIAGA, E. (1997), Violence as a public health problem: socializing adolescents in the 1980's in Rio de Janeiro. Trabalho apresentado na IUSSP III ${ }^{\text {rd }}$ General Conference, Beijing, China, 11-17 de outubro.

(1998), Violence, civil rights and demography in Brazil: the case of the metropolitan area of São Paulo. Trabalho apresentado no Research Committee 41 (Sociology of Population), International Sociological Association's XIV Congress of Sociology, Montreal, $26 \mathrm{de}$ julho a $1^{\circ}$ de agosto.

DURKHEIM, É. (1988), Les rèdles de la méthode sociologique. Paris. Flammarion.

ELSTER, J. (1990), The cment of society. Nova York, Cambridge University Press.

FARLEY, R. (1988), "After the starting line: blacks and women in an uphill race". D emography, 25, 4: 477-495.

FERREIRA, C.E.C. e CASTINHEIRAS, L.L. (1996), “O aumento da violência entre jovens adultos e as transformações no padrão da mortalidade paulista". Como V ai? População Brasileira, Brasília, ano 1, 3: 6-12.

FIBGE - Fundação Instituto Brasileiro de Geografia e Estatísitca. (1980), Censo de população.

. (1991), Censo de população.

$\overline{\mathrm{RO}} \mathrm{M}$.

(1995), A nuário estatístioo do Brasil. CD-

(DEPIS). (1997), Tábuas de mortalidade. Brasil e regiões. Versão preliminar. Mimeo.

. $(1979,1980,1981,1990,1991,1992), \quad$ Esta-

tísticas do Registro Civil.

. (diversos anos), Tabulações especiais da PNADD.

FREUND, J. (1979), "La violence et ses rapports avec la ville et les communautés", in M. Massesoli e A. Bruston (eds.), V iolence et transgression, Paris, Anthropos, pp. 35-59.

FUNDAÇÃO SEADE. (1994), "Mortalidade e sobrevivência no Estado de São Paulo". Informe De mográfico, 26.

GOLD, R. (1970), "Urban violence and contemporary defensive cities". Journal of the A merican Institute of Planners, XXXVI, 3: 146-159.
GREEN L.W. e KREUTER M.W. (1991), H ealth promotion planning: an educational and environmental approach. $2^{\text {a }}$ ed., Mountain View, CA, Mayfield Publishing Company.

GUEDES, A.C.D. (1996), "A evolução da mortalidade por causas de morte no Distrito Federal entre 1980 e 1990". A nais do X Enoontro Nacional de E studos Populacionais, vol. 4: 1.989-2.016.

GUERRERO, R. (1997), Prevención de la violencia a través del control de sus factores de riesgo. Trabalho apresentado na reunião El D esafio de la Violencia Criminal Urbana, promovida pelo Banco Interamericano de Desenvolvimento (BID) e 0 Estado do Rio de Janeiro, Rio de Janeiro, 2-4 de março.

JOZAN, P. (1989), "Contrasts in mortality trends". Proceedings of the International Population Conferenœ, Nova Déli, vol. 3: 231-245.

LOPES, A.G.S. (1994), "Mortalidade por causas externas e alguns aspectos da qualidade dos dados". Boletim Técnion, CIDE, 9, março.

MADEIRA, F. e BERCOVICH, A. (1992), "A onda jovem e seu impacto na população economicamente ativa masculina em São Paulo". Planejamento e Políticas Públicas, Brasília, IPEA, 8, dezembro.

MARTINS, J. de S. (1989), "Linchamentos: a vida por um fio". Travessia - Revista do Migrante, São Paulo, Centro de Estudos Migratórios, 2(4), mar.-ago.: 21-27.

MELLO JORGE, M. Helena P. de. (1988), Investigação sobre mortalidade por acidentes e violências na infância. Tese de livre-docência, São Paulo, Faculdade de Saúde Pública, Universidade de São Paulo.

. (1998), "Como morrem nossos jovens", in Comissão Nacional de População e Desenvolvimento, Jovens acontecendo na trilha das políticas públicas, Brasília, CNPD, pp. 209-292.

MERCY J.A. et al. (1993), "Public health policy for preventing violence". $\mathrm{H}$ ealth A ff., Winter: 7-29.

MINAYO, M.C. (1994), "A violência social sob a perspectiva da saúde pública". Cadernos de Saúde Pública, Rio de Janeiro, Escola Nacional de Saúde Pública, Fundação Oswaldo Cruz, (10)1: 7-18.

MINISTÉRIO da SAÚDE. (1996), Sistema de informagoes sobre mortalidade. Dados das declaracoees de óbito. 1979-1995. Fundação Nacional da Saúde, CENEPI/ D ataus. CD-ROM. 
MOREIRA, M.M. (1996), "Evolução da mortalidade adulta em Pernambuco. 1930/ 40-1970/ 80, 1974/ 76-1979-81", A nais do X Encontro N acional de E studos Populacionais, vol. 4: 1.925-1.943.

MURRAY, C.J.L. e LÓPEZ, A.L. (1996), “Estimating causes of death: new methodologies and global and regional applications for 1990", in C.J.L. Murray e A.L. López (eds.), The global burden of disease: a comprehensive assessment of mortality and disability from diseases, injuries and risk factors in 1990 projected to 2020, Harvard University Press, p. 158.

NCIPC - National Committee for Injury Prevention and Control e CDC - Center of Disease Control. (1989), "Injury prevention: meeting the challenge". A merican Journal of Preventive Medicine, 5 (suppl.):1.992-2.203.

PAES, N.A. (1996), "A mortalidade por causas no Brasil: qualidade de comportamento dos dados". A nais do X Encontro Nacional de Estudos Populacionais, vol. 4: 1.945-1.969.

PAGLIARO, E. (1996), "A mortalidade por violências e acidentes no Brasil". Como V ai? População Brasileira, Brasília, ano 1, no especial, junho: 10-12.

PAIXÃO, A.L. (1990), "A violência urbana e a Sociologia: sobre crenças e fatos e mitos e teorias e políticas e linguagens e.... ". Religião e Socie dade, 15, 1: 68-81.

PALLONI, A. (1993), "D esign problems and data collection strategies in studies of mortality differentials", in E. Arriaga (ed.), Readings in population research methodology. $\mathrm{V}$ ol. 2: M ortality research, Chicago, United Nations Population Fund.: 7-44/ 7-58.

PHEBO, L. (1996), "A violência como fato epidemiológico". Saúde em Foco, Secretaria Municipal de Saúde do Rio de Janeiro, ano V, 13: 4-6.

PINHEIRO, P.S. (1991), Democracia, direitos humanos e desenvolvimento econômico e social: obstáculos e resistências. O caso do Brasil. Trabalho apresentado no Seminario Latinoamericano de Expertos em Derechos Humanos, Democracia y Desarrollo Economico y Social, Santiago, Chile.

PINHEIRO, P.S. et al. (1991), "Violência fatal: conflitos policiais em São Paulo". Revista USP, 9: 95-112.

POLLARD, J.H. (1988), "On the decomposition of changes in the expectation of life and differentials in life expectancy". D emography, 25(2): 265-276.
. (1996), "On the changing shape of the Australian mortality curve". Health Transition Review, supplement 6: 283-300.

REICHEMHEIM, M. e WERNECK, G. (1994), "Anos potenciais de vida perdidos no Rio de Janeiro, 1990. As mortes violentas em questão". Cadernos de Saúde Pública, Rio de Janeiro, Escola Nacional de Saúde Pública, Fundação Oswaldo Cruz, 10, 1: 188-198.

REISS, J.A. e ROTH, J.A. (eds.). (1993), Understanding and preventing violence. Washington, National Academy Press.

RODRIGUES, G.C., FONSECA, M.C. e RODRIGUES, R.N. (1996), "Índices de mortalidade por sexo e seu impacto no mercado matrimonial". A nais do X Enoontro Nacional de Estudos Populacionais, vol. 4: 1.909-1.924.

ROTH, J.A. (1994), "Psychoactive substances and violence". Research in Brief, Washington, US Dept. of Justice, fevereiro.

SOUZA, E.R. de. (1994), "Homicídios no Brasil: o grande vilão da saúde pública na década de 80". Cadernos de Saúde Pública, Rio de Janeiro, Escola Nacional de Saúde Pública, Fundação Oswaldo Cruz, 10, 1: 45-60.

UNITED NATIONS. (1990), "Population and human rights". Proceedings of the Expert Group $\mathrm{M} \in$ ting on Population and $\mathrm{Human}$ Rights, Genova, 3-6 de abril 1989.

VALLIN, J. (1993), "Socioeconomic determinants of mortality in industrialized countries", in E. Arriaga (ed.), Readings in population research methodology. V ol. 2: M ortality research, Chicago, United Nations Population Fund.: 9-57/971. (Trabalho apresentado originalmente no Meeting on Socioeconomic Determinants and Consequences of Mortality, Mexico, DF, 19-25 de junho de 1979.)

VASCO NCELOS, A.M.N. (1996), "Estatísticas de mortalidade por causas: uma avaliação da qualidade da informação". A nais do X Encontro $\mathrm{N}$ acional de Estudos Populacionais, vol. 1: 151-166.

WALDVOGEL, B. (1992), "Os números da AIDS. São Paulo surpreende". São Paulo em Perspectiva, São Paulo, Fundação SEADE, 6, 4, out.-dez.

WRIGGINS, W.R. (1988), Youth cohorts, population change, and politics: five intervening variables. Trabalho apresentado na Conference of Future Changes in Population and Age Structure, Sopron, Hungria. 